\title{
O DIA DO JUÍZO OU O DESCOBRIMENTO DA ALMA - IMAGEM E TEMPO EM MÁRIO DE ANDRADE E GIORGIO AGAMBEN
}

THE DAY OF JUDGMENT OR THE DISCOVERY OF THE SOUL - IMAGE AND TIME IN MÁRIO DE ANDRADE AND GIORGIO AGAMBEN

\author{
Nilcéia Valdati ${ }^{1}$
}

Resumo: Para elaboração deste artigo, partimos da noção de profanação construída por Giorgio Agamben, vemos como ela é essencial para entendermos a constituição de categorias em torno da imagem, como "fantasma", "pathosformel" e "juízo final". Lançamos essas ideias em diálogo com Mário de Andrade fotógrafo e prosador em $\mathrm{O}$ turista aprendiz e Balança, Trombeta e Battleship Ou o descobrimento da alma, assim o que se tem como resultado são questionamentos sobre a elaboração da imagem, que independentemente do tipo de texto (fotografia, diário, conto, romance) coloca-se como carregada de tempo.

Palavras-chave: profanação; imagem; Giorgio Agamben; Mário de Andrade.

\begin{abstract}
The elaboration of this article started from the notion of profanity built by Giorgio Agamben; we analyzed how its meaning is essential to understand the constitution of categories around image, such as "ghost", "pathosformel" and "final judgment". We launched these ideas in dialogue with the photographer and prosaist Mário de Andrade in $\mathrm{O}$ turista aprendiz $e$ Balança, Trombeta e Battleship Ou o descobrimento da alma, so that what there is as a result are questions about the development of image, that regardless the type of text (photograph, diary, short story, novel) is placed as full of time.
\end{abstract}

Keywords: profanation; image; Giorgio Agamben; Mário de Andrade.

1 Doutora em Literatura pela UFSC. Professora na UNICENTRO-PR. 


\section{Profanação}

A partir de um termo ligado à tradição teológica, que implica a condição de estar fora do templo, mas nem por isso longe dele, (pro - "diante de" + fanum- "lugar consagrado aos deuses, templo"), Agamben (2005) vê nessa condição a maneira de restituir aquilo que era do sacro ou do religioso ao livre uso comum dos homens, ao uso político, ou ainda, biopolítico, desativando os dispositivos do poder e restituindo os espaços que eles haviam confiscado. Ou seja, a coisa mesma (AGAMBEN, 1984) que a religião separou pode ser tocada a partir de um dispositivo que acione um contato, tornando, desta forma, o dispositivo foucaultiano o próprio gesto profanador de Agamben. Isso talvez explique porque o texto "Elogio da profanação" se transforme em outro, "O que é um dispositivo?". Desse modo, o conceito de profanação seria "[...] um contrapositivo que devolveria ao comum aquilo que o sacrifício havia separado e dividido." (AGAMBEN, 2005, p.21)

Ao se considerar que na montagem das categorias históricas e linguísticas o essencial é o tempo, que, ao ser tomado por uma rachadura no fluxo contínuo da história, se vê imerso numa soleira, num dentro-fora do próprio evento que o constitui (AGAMBEN, 1996) ${ }^{3}$, veremos como a profanação se monta nesse mesmo movimento do tempo. Desta forma, é necessário pensar o que permeia a profanação: o que permite o contagio da teologia e da vida humana no gesto agambeniano? Ou ainda, por que aquilo que é próprio da imagem é do político, aquilo que é da estética é da ética, aquilo que é do homem é do divino, aquilo que é da linguagem é do silêncio, aquilo que é de Benjamin é de Foucault, aquilo que é de Bergamin é de Warburg e vice-versa.

2 O texto "Elogio della profanazione", publicado na Itália em 2005, junto aos curtos ensaios de Profanazioni [Boitempo, 2007], é apresentado quase na íntegra, numa das conferências proferidas por Giorgio Agamben na sua passagem pelo Brasil em 2005, como "Che cosè um dispositivo?". Texto traduzido para o português e publicado, no ano seguinte, pela revista $\mathrm{Ou}$ tra Travessia. Posterior à publicação brasileira, sai na Itália, em 2006, pela editora Nottetempo o mesmo texto com algumas alterações, como o mesmo título "Che cosè um dispositivo?".

3 Em 1996 Giorgio Agamben reúne em Categorie italiane uma série de textos publicados de maneira esparsa durante as duas décadas anteriores. Com o estudo da poética como fio condutor, o livro é a proliferação de um projeto inacabado para uma revista, que, sem título, tinha em uma das seções o propósito de "identificar, através de uma série de conceitos polarmente conjugados, nada menos que as estruturas categoriais da cultura italiana" (AGAMBEN, 1996, p.VII). Era entre 1974 a 1976, Agamben mais dois amigos italianos, Ítalo Calvino e Claudio Rugafiori, encontravam-se em Paris, e durante as frequentes reuniões e discussões chegaram a uma lista de categorias: Rugafiori defendia a ideia de "arquitetura/vagueza", como aquilo que possui o domínio da ordem matemático-arquitetônica junto com a percepção da beleza como coisa vaga; Calvino "velocidade/leveza"; Agamben "tragédia/comédia", "direito/criatura", "biografia/fábula". 
Em “José Bergamin", de 1972, ensaio escrito para a primeira edição da tradução para o italiano do livro Decadenza dell'analfabetismo, pela marginal editora Rusconi, Agamben (1972) constrói Bergamin sob o signo da fronteira: o teatro do século de ouro espanhol e o romantismo alemão; a mortificação e a autotrancendência da "situação crítica"; o enciclopédico (analfabetismo) e o cientificismo.

O objeto da crítica (e também o seu ponto de coincidência com a poesia) é de fato, para Bergamin, a 'situação crítica da obra', no dúplice sentido, o de mortificação e de autotrancendência. Isto explica a existência com a qual ele volta sobre o conceito de limite, de 'fronteira' da obra de arte [De la naturaleza y figuración fronteriza de la poesía é o subtítulo de uma das obras críticas mais importantes, Beltenebros, e Fronteras Infernales de la Poesía é o título de uma reunião de ensaios de 1959] que fornece em um certo sentido o eixo de seu pensamento crítico: a obra de arte é com efeito verdadeiramente a si mesma (se ensimisma, diz Bergamin) só quando toma consciência dos seus limites; mas o limite não é aqui simplesmente aquilo que a individualiza e separa, mas também aquilo que abre e sinaliza além dela; é, na verdade, segundo a lúcida fórmula de Bergamin, 'geradora de transcendência'. A relação crítica autêntica com a obra de arte é então o que a reconduz sempre a este limite essencial, em que ela nega e ao mesmo tempo transgride a si mesma, se ensimisma no momento mesmo em que sai de si. (AGAMBEN, 1972, p.10-11)

O que Agamben ainda não nomeava de soleira [soglia], mas sim de limite, fronteira ${ }^{4}$, é a tarefa fantasmagórica da crítica. Agamben lembra

4 Em La comuità che viene, no fragmento "Fuori", Agamben diz que a noção fuori significa "às portas" (fores é, em latim, a porta da casa; thyrathen, em grego, vale literalmente "à soleira"). O fuori não é outro espaço que está além do espaço determinado, mas ele é a passagem, a exterioridade que lhe dá acesso. A soleira não é, deste modo, uma outra coisa em relação ao limite, ela é, por assim dizer, a experiência do limite mesmo, o "esser-dentro un fuori" (AGAMBEN, 1990). No entanto, a ideia de soleira, que as traduções brasilerias têm optado por limiar, parece ter passado por mudanças no pensamento de Agamben. Entre a primeira edição de La comunità che viene, em 1990, e a segunda, em 2001, ocorreram alterações no uso de algumas categorias: onde na segunda, pela paráfrase acima, lê-se soleira [soglia], na primeira lê-se limite; onde na segunda lê-se limite, na primeira lê-se barreira - esta última totalmente excluída não só na última versão de La comunitá che viene, mas também dos últimos trabalhos de Agamben.

$\mathrm{O}$ que aparentemente muda toda uma categoria, o fuori, radicaliza a ideia de movimento na construção do pensamento, da leitura, das categorias em Agamben. Dentro desse movimento, em que a profanação, com sua capacidade de toque, dá possibilidade ao arranjo textual, vê-se 
que o poeta, ensaísta, teatrólogo, teólogo e polemista foge a qualquer uma dessas definições em sua obra, para assumir a de fantasma. Através das palavras de Victor Hugo, esclarece que

Bergamin ama definir a si mesmo como um fantasma. Para compreender o que significa esta definição, ela é colocada em relação com a palavra que, a morte chama pela mão mediânica: 'Todo grande espírito', diz a morte, 'faz em sua vida duas obras: sua obra de vivente e sua obra de fantasma', e acrescenta: 'Faça vivente sua obra de fantasma'. (AGAMBEN, 1972, p.15-16).

Ou seja, a ideia de fantasma, ou de fantasmagoria, está extremamente ligada à de linguagem e de imagem, como a de "sociedade do espetáculo", em Guy Debord (AGAMBEN, 1990). Vale lembrar que esse texto sobre Bergamin é escrito pouco antes de Agamben iniciar, sob influencia da linguística de Émile Benveniste, suas pesquisas no Warburg Institute sobre linguagem e melancolia. Trabalho que dará vida em Stanze: La parola e il fantasma nella cultura occidentale, em 1977 e que será potencializado, em 2004, em Nymphae, texto no qual Aby Warburg é o fantasma, ou melhor, pathosformel. Desta forma, não somente pela lógica linear, mas também pela construção que Agamben faz das figuras de Bergamin e Warburg, vê-se uma aproximação entre eles, a partir da ideia de fantasma, no primeiro, e pathosformel, no segundo.

Em 1975, o filósofo italiano redige o seu primeiro trabalho sobre Warburg, como parte de um projeto que se propunha a compor uma série de retratos dedicados a personalidades exemplares, que representassem uma ciência humana. Não ao acaso o texto sobre Warburg se intitula "Warburg e la scienza senza nome". O projeto não teve continuidade, apenas um segundo nome compôs a lista, Ėmile Benveniste, mas o texto nunca foi concluído. No entanto, será em Nymphae, publicado em livro em 2007 como Ninfe, que a ideia de pathosformel será discutida. Partindo do questionamento de como uma imagem pode carregar-se de tempo, Agamben (2004) encontra em Domenico da Piacenza, com o seu tratado Dela arte di ballare et danzare, escrito por volta de 1400, um dos elementos fundamentais da dança, a fantasmata: "um instante imprevisível entre dois movimentos, capazes de contrair virtualmente na própria tensão interna a medida e a memória de toda uma série coreográfica" (AGAMBEN, 2004, p.54). Para Domenico a dança é

emergir a ética como modo de fazer com que a soleira não assuma novamente a forma de barreira, nem que fique totalmente fora. Assim, a ética atesta o estar entre, o estar dentro-fora. 
uma operação conduzida pela memória, uma composição por fantasmas em uma série temporalmente e espacialmente ordenada. Desta forma, o lugar do dançarino não está no corpo e no movimento, mas sim na imagem como "cabeça de medusa", como pausa não imóvel, carregada, ao mesmo tempo, de memória e de energia dinâmica, o que leva a crer que a essência da dança não é mais o movimento, sim o tempo. Agamben (2004) acredita que Warburg tivesse conhecimento deste tratado quando preparava, em Firenze, seus estudos sobre Costumi teatrali per gli intermezzi del 1589.

É certo que nada se assemelha mais a sua visão da imagem como Pathosformel do que a da 'fantasmata', que contrai em si, em uma brusca parada a energia do movimento da memória. [...] O conceito de Pathosformel aparece pela primeira vez no ensaio de 1905 sobre Dürer e l'antichità italiana, que reconduz o tema iconográfico de uma incisão dureriana à 'linguagem gestual patética' da arte antiga, através de uma Pathosformel testemunhada em uma pintura vascular grega, em uma incisão de Mantegna e nas xilografias de um incunábulo veneziano. É necessário, antes de mais nada, prestar atenção ao termo mesmo. Warburg não escreve, como teria sido possível, Pathosform, mas Pathosformel, fórmula de pathos, sublinhando o aspecto estereotipado e repetitivo do tema imaginal com o qual o artista sempre media-se para dar expressão à 'vida em movimento' (bewegtes Leben). Talvez o melhor modo de compreender o seu sentido é aproximá-lo ao uso do termo 'fórmula' nos estudos de Milman Parry sobre o estilo formular de Homero, publicados em Paris nos mesmos anos em que Warburg trabalhava sobre o atlas Mnemosyne (AGAMBEN, 2004, p.55).

Como a dança, que produz uma parada, uma interrupção no fluxo do movimento, o registro fotográfico capta o momento exato em que essa quebra se instaura. Em Il giorno del giudizio ${ }^{5}$, Agamben (2007, p.27) se pergunta: "o que me fascina e me mantém encantado nas fotografias que amo?" A resposta indica para as fotografias que carregam "o lugar do juízo universal". Como as fotografias de Mario Dondero que poderiam ser resultado da flânerie, ou o andar à deriva, captados pelo fotógrafo. Nas palavras

5 O breve ensaio foi publicado em um pequeno livro em 2004, na coleção I Sassi, da recém-criada editora Nottetempo, seguido de um outro "Gli aiutanti", além de quatro fotografias de Mario Dondero e um daguerreótipo. Em 2005 os dois textos, sem as fotografias, são inseridos em Profanazioni [Roma: Nottetempo, 2005]. Livro traduzido e publicado no Brasil em 2007, a qual será utilizada para as citações. 
de Agamben (2007, p.27) "passeia-se sem meta e se fotografa tudo 'o que aparece. Mas 'o que aparece' - o rosto de duas mulheres que passam de bicicleta na Escócia, a vitrina de uma loja em Paris - é convocado, é citado para comparecer no Dia do Juízo".

Para exemplificar tal situação retoma a história da fotografia, quando Louis-Jacques-Mandé Daguerre registra a primeira figura humana em uma fotografia em Boulevard du Temple. Agamben (2007) explica que provavelmente o boulevard estivesse cheio de pessoas, mas por conta dos equipamentos da época necessitarem de muito tempo de exposição não se pode ver toda essa massa. A figura que aparece na foto é a silhueta de um homem em pé que se fazia engraxar as botas, que por ter ficado muito tempo parado foi captada pelo equipamento. A multidão se faz presente no registro, mas não se vê. Apenas aquela pessoa foi captada no seu gesto mais banal, mais cotidiano e ordinário. Este gesto é que corresponde ao Juízo Final, pois "graças a objetiva fotográfica, o gesto aparece carregado com o peso de uma vida inteira; aquela atitude irrelevante, até mesmo boba, compedia e resume em si o sentido de toda uma existência" (AGAMBEN, 2007, p. 28).

Um outro gesto que o pensador italiano encontra nas fotografias que ama é a exigência do fotografado em relação a quem o olha. Exige o seu nome, exige que não seja esquecido. Como a menina que estampa o livro Terra de Sebastião Salgado (1997). "(No estúdio onde trabalho, sobre um móvel do lado da escrivaninha, está a fotografia - aliás, bastante conheci$\mathrm{da}$ - da do rosto da menina brasileira que parece fixar-me severamente, e sei com absoluta certeza que é e será ela a julgar-me, tanto hoje como o último dia" (AGAMBEN, 2007, p.29). A exigência da fotografia assim para ele, é sempre uma exigência de redenção, em que a imagem fotográfica é certamente mais que uma imagem "[...] é o lugar de um descarte, de um fragmento sublime entre o sensível e o integível, entre a cópia e a realidade, entre a lembrança e a esperança". (AGAMBEN, 2007, p.29)

Em síntese, ao montar categorias como fantasmata, pathosformel, juízo final Agamben coloca em jogo as fissuras do tempo, coloca em jogo pensadores como Aby Warburg, Jose Bergamin e Walter Benjamin. E nesse jogo o que aparece é a profanação.

\section{O descobrimento da alma}

Uma soleira se faz necessária. Lançamos um olhar para o fotógrafo, prosador e Turista aprendiz Mário de Andrade e pensemos: se Agamben destaca 
as fotografias que ama e esclarece porque as ama, Mário de Andrade apresenta o que ele ama no gesto fotográfico retido pela sua "codaquinha". Mário se aproximaria de Bergamin, de Warburg, de Benjamin, da ideia de fantasma, ninfa, de fórmula de pathos, só para lembrar alguns nomes e imagens citados acima para desvendar o movimento profanatório de Agamben, na montagem de seu método, em que a imagem torna-se carregada de tempo.

Enquanto turista aprendiz Mário realiza duas grandes viagens. A primeira, em 1927, à região norte, e a segunda, em 1928-1929, à região nordeste, as quais lhe rendem diários textuais e fotográficos, inclusive com legendas aos registros imagéticos. A primeira, entre maio e agosto de 1927, é organizada por D. Olivia Guedes Penteado, que leva como companhia a sobrinha Magarida Guedes Penteado (Mag) e a filha de Tarsila do Amaral, Dulce do Amaral Pinto (Dolur). Com as três, Mário vai ao Amazonas, Pará, Porto Velho, Iquitos e à fronteira com a Bolívia, tudo isso de vapor, com escalas nos principais portos; em embarcações típicas, navega os rios da região, igapós e igarapés e ainda toma o trem Madeira-Mamoré. Na segunda, do final de 1928 até fevereiro de 1929, anda por Alagoas, Rio Grande Norte, Paraíba e Pernambuco. (LOPEZ, 2005)

Interessa-nos, aqui, a primeira viagem e as quatro figuras que viajam pelo norte: Mario, D. Olivia, Mag e Dolur. No dia 08 de julho de 1927, Mario regista com sua "codaquinha" os rostos das duas meninas, que, de uma porta entre-aberta, provavelmente de cabine, olham e sorriem para câmera, gesto que é narrado, um mês antes, dia 18 de junho, quando Mário descreve um episódio protagonizado pelas jovens, que envolve as quatro personagens:

Eram quase três horas da manhã e a rainha do Café fazia muito se recolhera. Acordamos o homem do bar, na intenção de tomar um alcoolzinho forte, evitando algum resfriado. Tomei meu gole, e fui na cabina trocar minha roupa encharcadíssima, deixando as moças com o moço fiscal. Não demorei talvez quinze minutos, mas assim que cheguei no bar, percebi o estrago. Não sei o que o rapaz apostou com as moças, e elas, liberdosas de educação, tinham bebido muito, cálice de pinga sobre cálice. Não durou muito, mandei tudo pra cabina, principiou uma bulha escusa na cabina delas que, se de um lado pegava com a minha, do outro vizinhava com a da criada de D. Olivia, esta logo em seguida. Aos poucos a bulha aumentou. Eram lamentos doloridos de Trombeta, ao passo que Balança me chamava pelo nome, entre risadas de não poder mais. Eu incomodadíssimo, se a rainha acordasse e fosse ver... encontrava as duas completamente bêbadas. E 
eu que estava desde o princípio da viagem engolindo coisas, pra evitar desgostos de D. Olivia... - O que é, Balança! Por favor, fique quietinha! E vinha, agora mais claro o choro de Trombeta, me chamando. Me vesti às pressas, e saí no deque. O que havia de ver! Elas, porta da cabina escancarada, Balança deitada no chão da cabina. Trombeta na cama, com as pernas no chão, agarradas por Balança. É que Trombeta, nem com ajuda de Balança, conseguira arrancar uma das botas que trazia, e agora! Nisto ascendem luz na cabina de dona Olívia, fiquei estarrecido. Apagaram a luz. Mas se alguém me visse entrar ou sair da cabina das moças, elas já iam tão mal faladas, eu sabia, por causa de suas liberdades modernas!... E os lamentos de Trombeta tendiam a aumentar. E os esforços de balança a faziam rolar no chão da cabina, cada vez rindo abafado mais. Acendem de novo a luz, é dona Olívia. Aviso com gesto. Apagam a luz, ah, não pude mais! Morres de fraco? Morres de atrevido, murmurei com Bocage, disse uma bocagem por dentro, entrei, arranquei a bota de Trombeta. Vontade de bater. (ANDRADE, 1993, p.34)

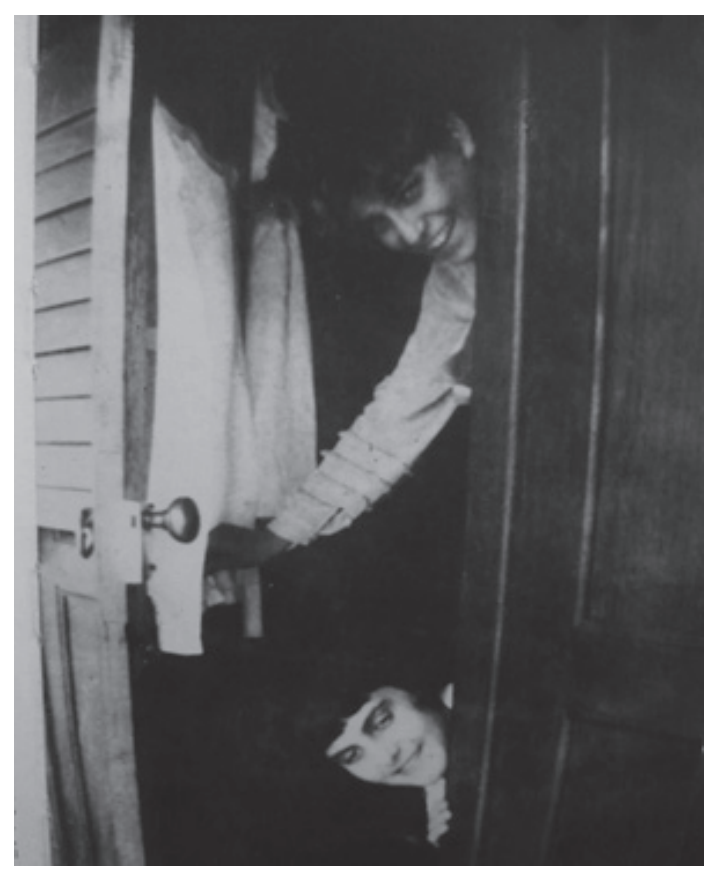

Figura 1: Rio Madeira / Ritmo [Mag e Dolur], 8-7-27. Fonte: Lopez (1993, p.34)

Organon, Porto Alegre, v. 31, n. 61, p. 287-301, jul/dez. 2016. 
Os dois registros, com um intervalo de um mês, por um lado, evidenciam a relação entre as quatro figuras e o cotidiano da viagem; por outro, atestam a inserção a um "espaço" intocável: uma geografia brasileira sendo descoberta, junto a figuras que se descobrem a si mesmas. Descobertas contidas no gesto fotográfico, que, ao fixar e condensar uma viagem inteira em instantes, "aparece carregado com o peso de uma vida inteira" (AGAMBEN, 2007, p.28), por isso, cada fotografia se apresenta como "O dia do juízo".

Para Mário de Andrade, o "Juízo Final" aparece na viagem sob a forma de mulher, D. Olivia Guedes Penteado, mas também como D. Maria, em Balança, Trombeta e Battleship ou a descoberta da alma (ANDRADE, 1994). Conto que, inédito até 1994, é resultado dessa viagem à Amazoônia. No entanto, uma pequena parte desse texto, que fazia parte de um romance inconcluso, fora publicada por Mário, em 1940, na revista modernista portuguesa Presença. Por mais que este conto esteja ligado à viagem que resultou em O turista aprendiz, tem recebido pouca atenção da crítica, como nos lembra Silva (2015, p.69):
[...] apesar de contar com uma rigorosa edição genética e crítica de Telê Ancona Lopez, tem recebido pouca atenção da crítica, além de não ser mencionado pelo próprio autor em sua abundante correspondência, fato incomum que dife- rencia esse conto de outras produções, mesmo abortadas, de Mário de Andrade.

No conto, as três personagens títulos, mais Juízo Final têm a revelação do princípio vital, descobrem a alma por meio do contato com o desconhecido, o estrangeiro Battleship, jovem inglês, pickpocket, que viaja rumo a Argentina à procura de aventuras, mas num desvio de rota chega ao Rio de Janeiro, ruma até Minas Gerais e acaba se fixando em São Paulo para exercer os seus furtos. O personagem estrangeiro, na visão de Silva (2015, p.80), seria uma espécie de alter-ego do viajante Mário de Andrade no seu contato com um meio brasileiro inusitado: "A tentativa de integração do inglês ao meio brasileiro não deixa de ser semelhante à do turista aprendiz Mário de Andrade, cujo olhar empático e a tentativa de compreensão da diversidade cultural brasileira também se dá, inevitavelmente, a partir de fora".

Se Mário de Andrade é acompanhado pelas duas jovens e mais a senhora, Battleship, durante a sua atividade, conhece duas meninas, Balança e Trombeta, que vivem de pedir esmolas e bater carteiras. Seduzido por aquelas meninas sujas, Battleship passa a perseguí-las e chega à margem da 
cidade, onde depara-se com Juízo Final, "velha mulatona" que as explora. Nesse momento arma um jogo de sedução, apararentemente a fim de limpar a sujeira, que resulta num encontro amoroso.

Depois que entrou pela vereda do matinho ouviu um ruído de carreira atrás de si, virou. Era Trombeta sorrindo, sem compostura. Chegou junto dele, e contou que nem ela nem Balança chamavam dona Maria de 'dona Maria' entre si, mas de 'Juízo Final. Era também outra palavra que elas tinham pegado do padre no dia em que entraram na tal capela e escutaram o sermão, e tinham se entrebatizado pelas palavras engraçadas que escutaram da boca do padre. Então ela ficara Trombeta, e a companheira Balança. Dona Maria, principiaram chamando de Juízo Final e achavam muita graça, mas um instinto impossível de respeito, não, uma reserva de superioridade por quem não era igual a elas, fizera com que revelassem nunca pra velha que a chamavam de Juízo Final. E, de fato, sem perigo nenhum, diante de dona Maria uma falava pra outra:

_ Balança.

- Eu.

_ Juízo Final é isto, um palavrão.

Ambas se riam. (ANDRADE, 1994, p.435)

Os nomes da personagens, já forjados em O turista aprendiz, carregam um significado litúrgico, ou seja são ligados à religião com uma carga de culpa e castigo (trombeta anuncia o juízo final e balança determina os destinos). No conto, conforme Moraes (2015, p.11) "são ressignificados a partir de seu valor sonoro e ganham aspecto lúdico entre essas personagens". Além do aspecto sonoro e lúdico, percebemos a relação destes nomes com a noção de profanação anunciada por Agamben (2005): o que é do divino, passa a ser tocado pelo homem, que agora define o seu destino no instante presente.

Mário de Andrade (1994, p. 27), pela figura da velha Juízo Final, destaca o valor do momento presente: "se tratava sim duma espécie de abandono do passado, em quem só vivera e por quase cem anos já, da exclusiva precisão do momento". Não há outro tempo para ela e as outras personagens do conto. Um tempo que Moraes (2015, p.12) vai chamar de "momentaneidade":

Também Trombeta e Balança haviam sido contaminadas pela momentaneidade, foram tomadas pelo pensamento imediatista que exclui planejamento e preocupação com a necessidade de reserva e de futuro. [...] Não só Juízo Final, 
Balança e Trombeta viviam da momentaneidade; também Battleship se sustentava com o fruto de seus roubos imediatos, sem planos para o futuro e era assim que a vida dele se estruturara até ali. Daí a identificação com Trombeta, por isso sentia-se também um desgraçado. Mesmo assim, a ambivalência da proibição, representada pelo nojo à sujeira e o desejo de tocar, ainda o perturbam [...]

Nos três gestos de Mário de Andrade, do diário, da fotografia e do conto, Juízo Final surge ao fundo, como um fantasma, e exerce um controle sobre os instantes. É ele, ou melhor ela, que, sem praticar nenhuma ação aparente, determina as possibilidades da profanação através do poder que lhe é concedido, ou seja, o poder de reunir a todos e a tudo num único momento. Momento que está na imagem enquanto fotografia, mas também na imagem enquanto fantasma, pathosformel. No primeiro registro, esse momento acontece nos rostos das meninas que olham pela porta entre-aberta para serem retidas pela câmera, os olhares e sorrisos travessos pedem para serem tocados e congelados, não como simples lembrança de viagem, mas sim como o inesperado na viagem. No segundo registro, no traço da escrita, o mesmo instante se monta. A embriaguez das meninas, agora já nomeadas de Balança e Trombeta, coloca o narrador em estado de tensão pela perspectiva do surgimento do Juizo Final. No entanto, a tensão é o próprio registro, a própria imagem enquanto cabeça de medusa, é a única maneira daquele instante existir. No terceiro, Balança e Trombeta entram em contato com a descoberta da vida, da sexualidade, pelo contato com o estrangeiro Battleship. O controle de Juízo Final nada impede, antes incita esse gesto. Incita o contágio, incita a vida, incita a profanação.

Trombeta ia ficando aos poucos outra gente. Saíra debaixo da sujeira quase um anjo claro, anjo brasileiro, é certo, de olhos e cabelos muito escuros, e um corpo copiado da mulataria na esbeltez. Mas, insexuada como os anjos, a sensação que Trombeta nos dava era a de grave segurança no pudor. Se ficava tão calmo, contemplando a menina, como deve ser o sentimento de paz depois de uma guerra comprida. Assim Trombeta vinha saindo do riacho, esguia, quase um silvo, um silvo sim de cobra, eufônica junto dos mil ruidinhos que a natureza estava chorando naquele mato da manhã. Não se destacava nem se impunha, pé de carrapicho, pé de flor sem nome, bonita feito folha que a chuva lavou (ANDRADE, 1994, p. 36).

O corpo moreno de Balança emergia da limpeza parece que 
mais moreno, [...] quando o inglesinho quis levantar para se rever na obra pronta, ele percebeu que, erguido, havia de mostrar pra menina a indiscrição aguda em que se achava e teve um imenso dó. Agarrou sem brinquedo Balança pelo corpo e pelas pernas, suspendeu-a no colo e assim pôde se erguer nágua. Balança principiou chorando miúdo no ombro dele, e patinhando nágua, depois do lamedo, e afinal marchando na terra firme, Battleship carregou a menina até a vereda, onde o vestido azul a esperava para disfarçar a virgindade que eles tinham perdido nágua (ANDRADE, 1994, p. 39).

Este gesto de Mário encontramos em outros registros das viagens ao norte e nordeste do país, como no caso de "Sombra minha" e de "Roupas freudianas". No primeiro, Mario registra-se na "codaquinha" de forma que a sua sombra consegue captar o gesto do gesto, como indício de potência. No segundo, o movimento está retido pelo dispositivo da máquina e nele o instante em que as roupas no varal constatam o rapto do corpo. Enfim, as fotografias de Mario de Andrade sugerem a "presença" de um fantasma.

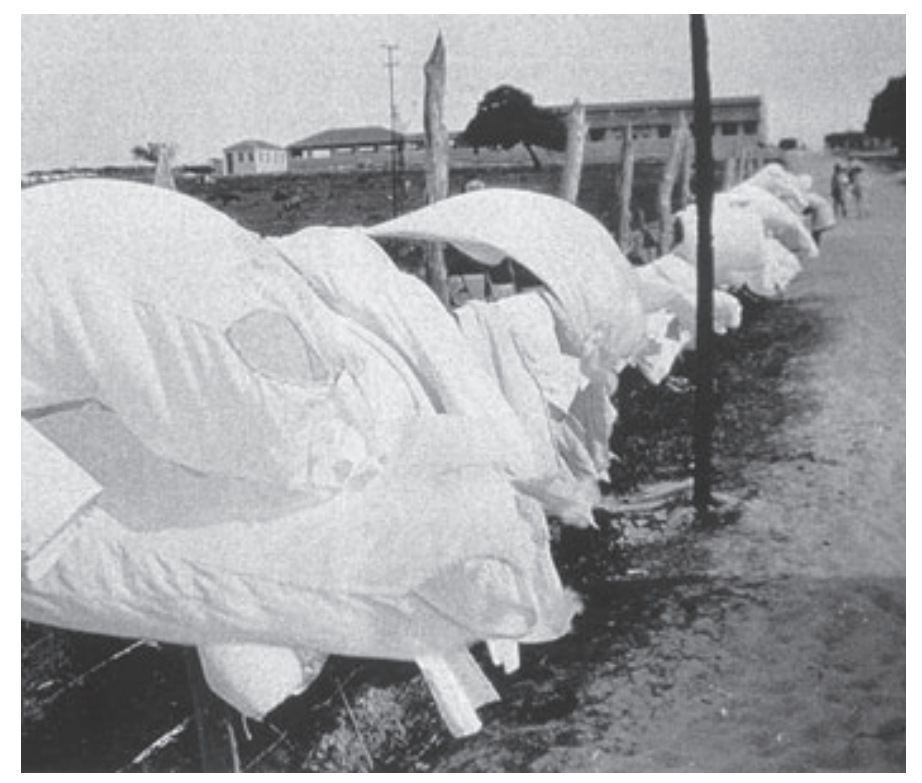

Figura 2: "Roupas freudianas / Fortaleza 5-VIII-27 / Sol 1 diaf..1/ Fotografia refoulenta / Refoulement" - Mário de Andrade. Fonte: Lopez (1993, p.15). 


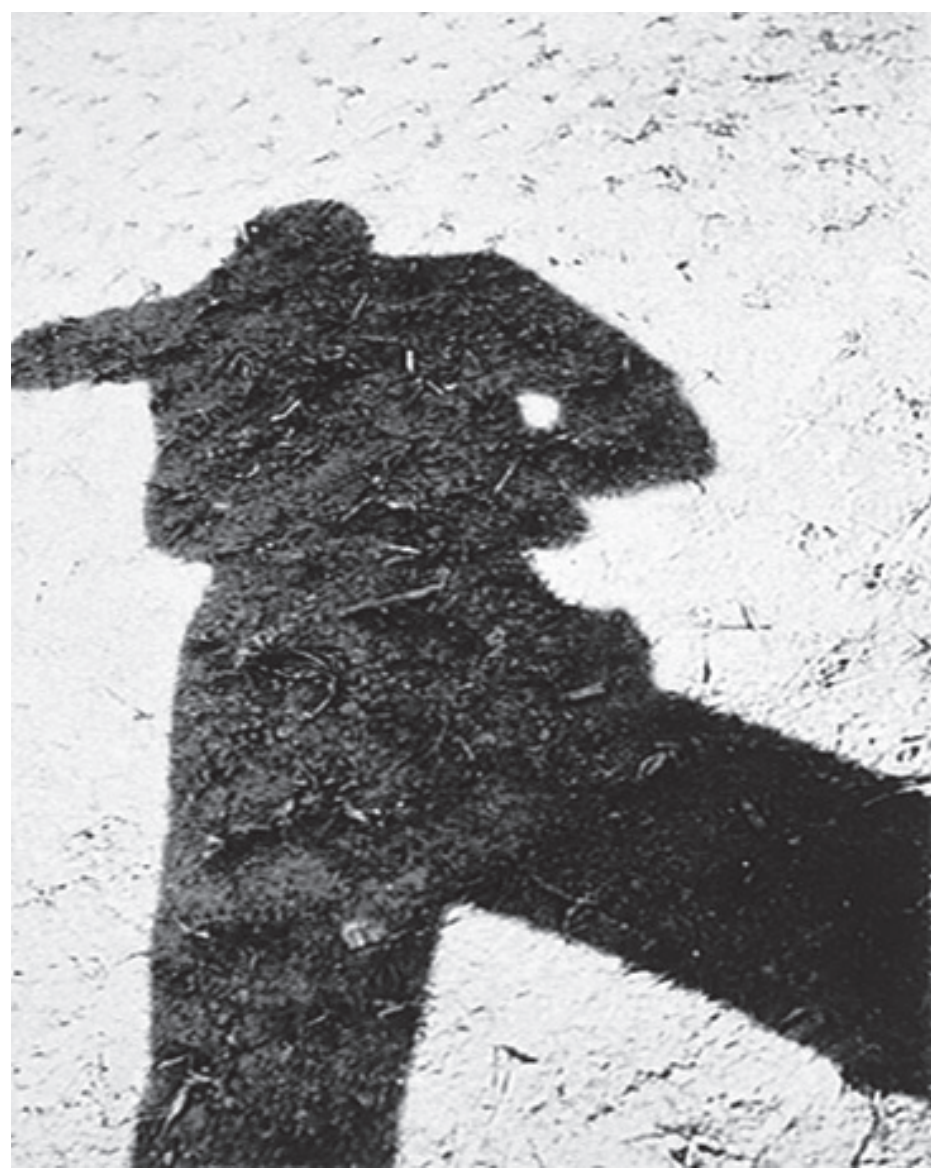

Figura 3: "Sombra minha / Santa Tereza do Alto / 1.I.28" - Mário de Andrade Fonte: Lopez (1993, p.contracapa).

Se para Agamben cada fotografia carrega o peso de uma vida inteira, o Juízo Final, Mário de Andrade, com seus registros fotográficos e escritos, nos faz pensar que a fotografia é o instante do nascimento, da descoberta da vida, do princípio vital. A profanação está no gesto do descobrimento da alma, enquanto toca a vida e devolve a ela o seu lugar de humano, enquanto restituiu o que era da imagem divina, à fotografia humana. Balança, Trombeta, Juízo Final, D. Olivia, Mag e Dolur, imagens humanas e divinas tocadas pelo autor como gesto - Mário de Andrade ou como fantasma. 
Desta forma, nesse jogo entre Mário de Andrade e Giorgio Agamben, nota-se que o Dia do Juízo (ou o Juízo Final) define a fotografia, a ninfa, ou a pathosformel, a vida em movimento que carrega em si a noção de tempo, a pausa não imóvel, o encontro com a "cabeça de medusa", figura tão recorrente nos trabalhos de Agamben. Assim como o fantasma em Bergamin pressupõe o se ensimesma da obra, e se tudo isso está no gesto de Agamben e como vimos também em Mário de Andrade, como não ver na profanação a marca de uma noção de tempo?

A passagem por esses elementos difundidos por Agamben e Mário mostra como no gesto de elaboração de suas imagens, há uma profanação do tempo: não são fixas, embora não sejam líquidas ou aéreas; são abertas, mas transitam por uma soleira que não as deixa escapar; são determinadas pela história, embora não sejam historicistas; respondem aos apelos que cada tempo suscita, mas não são lineares. $O$ tempo que as atravessa é o presente que une passado e futuro no instante da fotografia, do Juizo Final.

\section{REFERÊNCIAS}

AGAMBEN, Giorgio. José Bergamin. In: BERGAMIN, José. Decadenza dell'analfabetismo. Trad. it. Lucio D’Arcangelo. Milano: Bompiani, 2000 (1972), p.7-29.

. Aby Warburg e la scienza senza nome. Prospettive Settanta, ano 1, n.2, Roma: Associazione Culturale Settanta, jul./set. 1975. [Texto republicado, com o acréscimo de "Postilla 1983", em: Aut aut, n. 199/200, 1984, p. 51-66; Image et mémoire, 1998, p. 9-43; e La potenza del pensiero, 2005, p. 123-146.]

Stanze: la parola e il fantasma nella cultura occidentale.Turim: Einaudi, 1977.[Nova edição: Einaudi, 2006.]

. La cosa stessa. In: DALMASSO, Gianfranco (org.). Di-segno: la giustizia nel discorso. Milano: Jaca Book spa, 1984, p.1-12. (Republicado em Potenza del pensiero, em 2005].

. Idea de la musa. In: Idea de la prosa. Tradução de Laura Silvani. Barcelona: Ediciones Península, 1989, p.42.

Glosse in margine ai Commentari sulla società dello spettacolo. Democrazia e diritto, Roma: Editori Riuniti Riviste, ano XXX, n.3/4, maio/agosto 1990, p.81-92.

. Categorie italiane - studi di poetica. Veneza: Marsílio, 1996.

Le cinéma de Guy Debord. In: Image et mémoire. Paris: Editions Hoëbeke, 1998. 
. Nymphae. Aut aut, Milão: Il Saggiatore, n. 321/322, maio/agosto 2004, p. 53-67.

. Il Giorno del Giudizio. Roma: Nottetempo, 2004.

. Elogio della profanazione. In: Profanazioni. Roma: Nottetempo, 2005, p.83.

. O que é um dispositivo? Tradução de Nilcéia Valdati. Outra Travessia. Florianópolis, n. 5, 2005, p.9-16.

. Profanações.Trad. de Selvino Assmann. São Paulo: Boitempo, 2007.

. O dia do juízo. In: Profanações. Trad. de Selvino José Assmann.

São Paulo: Boitempo Editorial, 2007, p.29.

ANDRADE, Mário. Sem título. In: LOPEZ, Telê Ancona (org.) Mário de Andrade: fotógrafo e turista aprendiz. São Paulo: Instituto Estudos Brasileiros, 1993.

- Balança, Trombeta e Battleship ou o descobrimento da alma. São

Paulo: Instituto Moreira Salles; Rio de Janeiro: Instituto de Estudos

Brasileiros, 1994. [Edição Genética e crítica organizada por Telê Ancona Lopez].

LOPEZ, Telê Ancona. O turista aprendiz na Amazônia: a invenção no texto e na imagem. In: Anais do Museu Paulista. São Paulo, v.13, n.2, jul.dez. 2005, p.138-139.

MORAES, Ricardo Gaiotto de. Às (as) margens do outro: uma leitura de Balança, Trombeta e Battleship, de Mário de Andrade. Revista FronteiraZ, no 15, p.3-20, dezembro de 2015. Disponível em: <http://revistas.pucsp.br/ index.php/fronteiraz/article/view/24449/18557>. Acesso em: 15 maio 2016. SILVA, Júlio Cezar Bastoni da. Dimensão e situação de Balança, Trombeta e Battleship na obra de Mário de Andrade. Revista FronteiraZ, n ${ }^{\circ}$, p.68-86, dezembro de 2015. Disponível em: <http://revistas.pucsp.br/ index.php/fronteiraz/article/view/24449/18557>. Acesso em: 15 maio 2016.

Recebido em: 05/06/2016. Aceito em: 01/09/2016. 